Brazilian Journal
of Chemical
Engineering

ISSN 0104-6632

Printed in Brazil

www.abeq.org.br/bjche

Vol. 28, No. 03, pp. 467 - 473, July - September, 2011

\title{
NEUTRAL POLYETHYLENE OXIDE WITH A COFACTOR RECOMMENDED FOR PARTICLE FLOCCULATION
}

\author{
M. R. Abdallah/Qasaimeh*, F. Bani Hani and A. M. Dawagreh \\ Al-Balqa Applied University, Al-Huson University College, Chemical Engineering Department, \\ Phone: 9622 7010400, Mobile: 962 777439147, Fax: 96227010397 , \\ Irbid 21510, Al-Huson, P.O. Box 50, Jordan. \\ E-mail: qasaimeh@hotmail.com
}

(Submitted: September 14, 2010 ; Revised: January 24, 2011 ; Accepted: March 22, 2011)

\begin{abstract}
Conventional and neutral high molecular weight polyethylene oxide (PEO) adsorbs on some colloids and fines, flocculating them into flocs. Addition of a cofactor (CF) makes PEO adsorb on all types of colloids and fines, flocculating them into larger flocs. Homoflocculation of fines with PEO alone and with CF added prior to PEO were investigated in this work at low and high effective shear rates. CF role was investigated: it enhanced flocculation amplitude and rate by several magnitudes relative to PEO used alone, and was ascribed to the CF action to stiffen and extend PEO coils. Considering CF-PEO abilities in homoflocculation and in heteroflocculation as recorded in the literature, combination of homo- and heteroflocculation can now be applied to processes. Formed flocs and individual particles will simultaneously deposit onto fibers and, when filtered, particles will be retained in the fiber cake. This technique can be applied in industry processes and water treatment.

Keywords: Polyethylene oxide; Cofactor; Fines; Flocculation; Dispersion; Shear rate.
\end{abstract}

\section{INTRODUCTION}

Better retention aid systems are recommended in many processes to flocculate and retain colloids and fines. Fines are fiber fragments that pass 200 mesh pores $(76 \mu \mathrm{m})$ (Meng et al., 2007). Usually there are large amounts of dissolved and colloidal substances that interfere in the performance of ionic retention aids. Higher molecular weight, water soluble, neutral polyethylene oxide (PEO) is an alternative (Pelton et al., 1980). PEO was found to work but needed a cofactor containing a phenol group (Pelton et al., 1980). General cofactors used with PEO were phenol formaldehyde resin (PFR), tannic acid (TA), modified phenolic resin (MPR), sulphonated Kraft lignin (SKL), and sodium naphthalene sulphonate (SNS) (van de Ven, 1997; Meng et al., 2007). In some work, PEO was ineffective in clean water and effective in mill water (Pelton et al., 1980) due to dissolved lignin compounds. Tannic acid and phenol formaldehyde resin used with PEO were investigated as retention aids by Lindström et al., (1984). They found that, although PEO and phenolic resins do not adsorb on some colloids, fines, and fibers, this retention aid system was quite effective. They proposed a transient network mechanism that captures large fillers and passes small ones through network holes (Lindström et al., 1984). However, various researchers failed to find evidence for such a network. One evidence was dynamic light scattering experiments with PEO/SKL (Polverari et al. 1996). A second was experiments by Picaro et al. (1995) of retention aid solutions that passed packed beds. An alternative hypothesis to explain retention by $\mathrm{PEO} / \mathrm{CF}$ was a bridging mechanism, the case was clay deposition on fibers with PEO and SKL, while none adsorbed on fibers (Ishimaro et al., 1984). Van de Ven and Alince (1996) confirmed this result, argued network hypothesis, and showed fillers retention by a

*To whom correspondence should be addressed 
mechanism of association-induced polymer bridging describing two methods. Cofactor works as stiffness modifier or cofactor adsorbs first on surfaces facilitating for PEO adsorption, reducing PEO entropy and making it more compact.

Cofactors like Kraft lignin SKL, phenol formaldehyde, and phenol resins are assumed stiffness modifiers. Taking negatively charged SKL, the associated SKL-PEO coil behaves as a polyelectrolyte with negative PEO coil segments repelling each other, making the coil stiffer. Such stiffness causes extension of the PEO molecules, keeping them more expanded, which facilitates polymer bridging. This phenomenon was discussed by De Witt and van de Ven (1992), who considered two factors: electrical double layer thickness $\left(\mathrm{k}^{-1}\right)$, and adsorbed polymer layer thickness $(\delta)$. Particles stay separate by electrostatic repulsion for $\delta<\mathrm{k}^{-1}$, but when $\delta>\mathrm{k}^{-1}$ bridging may occur, in which the polymer layer extending out into the double layer adsorbs on another particle. To induce polymer bridging between particles, two methods can be used. In the first, a cofactor is added to PEO, making it a stiffer complex (Fig. 1(b)), and then this is added to the suspension to bridge the surfaces. In the second, a cofactor is added to the suspension to adsorb on the surfaces, followed by PEO, which will adsorb on the adsorbed cofactor, bridging the surfaces (Fig. 1(c)). When only PEO is added (Fig. 1(a)), PEO flexible chains will neither extend nor adsorb on surfaces and no bridging occurs (van de Ven et al., 1996). In filler (clay) deposition on fibers (heteroflocculation), the assumption that PEO alone cannot deposit clay on fibers was incorrect, since PEO caused flocculation by asymmetric polymer bridging. Here PEO acquires the ability to adsorb on fibers after first having been adsorbed on fillers. Such was also the case for fines, where PEO adsorbed on some fines, making other fines flocculate (Carignan et al., 1998). No clay deposition occurred when clay particles were incubated for a short time with an insufficient PEO coating; the bridging condition was not satisfied $\left(\delta<2 \mathrm{k}^{-1}\right)$. It is possible for PEO to adsorb first on clay, altering the polymer entropy and making it adsorb on fibers (van de Ven., 1994). Clay flocculation with TA or PFR added with PEO was followed by re-stabilization at excess PEO, polymer bridging at intermediate PEO, and steric stability at higher PEO, implying that TA and PFR act to extend the PEO layer thickness and thus induce bridging (van de Ven et al., 1996).

The PEO flocculation efficiency of particles by the bridging mechanism can be enhanced by adding $\mathrm{CF}$ or by using entangled PEO coils (entanglements). An entanglement, with a size larger than a single coil, is obtained with at least two interacting coils. Larger ones are obtained with more interacting coils. When PEO is added for flocculation in the entanglement state, the size of the polymer layer $\delta$ adsorbed on surfaces is multiplied, increasing the bridging efficiency. In the literature, a number of factors affected PEO flocculation efficiency. Some were in the flocculation process: salt content and type of fines (Abdallah, 2002; Meng et al., 2007; van de Ven, 2007). Others were in dissolution affecting the PEO entanglement state. The main factors in the dissolution unit were dissolution time, stirring intensity, concentration of PEO, aging, shearing and dilution after preparation (Abdallah, 2002; van de Ven et al., 2004). A further important factor was the CF to PEO ratio $(\varphi)$ added to the suspension at the recommended optimum value $\left(\varphi_{\text {opt }}\right)$ (Meng et al., 2009). Since the quantity of CF functions by bridging bonding, at $\varphi<\varphi_{\text {opt }}$ some PEO entanglements will not incorporate bridging, while at $\varphi>\varphi_{\text {opt }}$ excess negative CF will create repulsion among the particles; both cases cause a decrease in flocculation efficiency. Minerals are critical to retention of fines, which add optical characteristics to the paper sheet (Rank Brothers Ltd, England). Dissolved materials, evaluated as salt content and cationic demand, affect retention using ionic retention aid systems (van de Ven, 1993). Analysis of headbox pulp in the paper mill showed that fines comprise more than $50 \%$ and have major interactions (Abdallah, 2002).

In this work, the objective was to study the characteristics of fines flocculation with PEO alone and with CF-PEO retention aids, under low and high effective shear rate conditions.

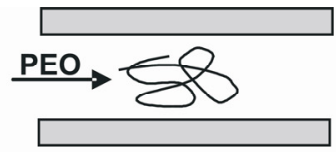

(a)

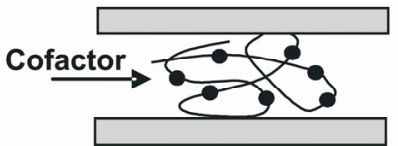

(b)

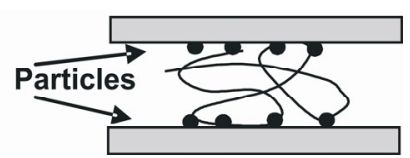

(c)

Figure 1: Association-induced polymer bridging: a) flexible chain does not adsorb onto surfaces; b) polymer adsorption and bridging occur when association stiffens the chain; c) polymer adsorption and bridging also occur when a cofactor links PEO molecule to surfaces. 


\section{EXPERIMENTATION}

The materials used in all experiments were fines separated from pulps by filtration and collected after passing 200 mesh pores and retention aid provided by (E.QU.IP Inc): PEO (flocc.999) of molecular weight $\mathrm{M}_{\mathrm{w}}\left(\approx 10^{6}\right)$ and $\mathrm{CF}$ (Interac 1323) having phenolic groups. Retention aid dosage ( $\mathrm{mg} / \mathrm{g}$ fines) added to all runs was constant at 0.08 for $\mathrm{PEO}$ and 0.18 for $\mathrm{CF}$, at constant $\varphi(=2.25)$ to eliminate any $\varphi$ factor effect. PEO used was at the same concentration, dissolution time, and added directly after preparation to eliminate dissolution factors. Factors studied were the roles of $\mathrm{PEO}, \mathrm{CF}$ and shear rate.

\section{Experimental Setup}

The experimental setup for the flocculation experiments at low shear rate with a beaker as flocculation vessel is shown in Fig. 2 (Abdallah, 2002). A fines suspension of $100 \mathrm{ml}$ and $0.1 \%$ consistency was added to a $250 \mathrm{ml}$ beaker, mixed at the lowest rate (rpm) with a magnetic stirrer in all runs, and circulated by a peristaltic pump through the photocell of a Photometric Dispersion Analyzer (PDA) (Rank Brothers Ltd, England). After reaching the steady state, CF was added followed by PEO. The PDA output signals: direct current voltage (Dc) and ratio $(R)$ of alternating current voltage to Dc, were displayed and plotted versus time by a recorder.

Fig. 3 (Abdallah, 2002) shows the experimental setup for the flocculation experiments at high effective shear rates with a high shearing pump fitted with a $2 \mathrm{~L}$ capacity feeding tank. The flocculation vessel, a tube loop of $5 \mathrm{~L}$ capacity with a diameter $\mathrm{d}(=2 \mathrm{r})=4 \mathrm{~cm}$, was connected to the output- input ends of the pump. The system has a controller regulating the flow velocity ( $\mathrm{v}$ ) within the Reynolds range $\operatorname{Re}(=2$ to 12$) \times 10^{4}$ and effective shear rate $\mathrm{G}_{\text {eff }}(=2$ to 20$) \times 10^{3}$; here $\mathrm{G}_{\text {eff }}=\mathrm{GRe}^{1 / 2}$ and $\mathrm{G}=\mathrm{v} / \mathrm{r}$ (Abdallah, 2002). The feed added to the loop was a fines suspension of $(0.1 \%)$ consistency, circulated at full feeding with no air bubbles in the loop. Bypass from the loop main stream was recycled to pass through the PDA photocell. At steady-state, $\mathrm{CF}$ was added prior to PEO; Dc and $\mathrm{R}$ were plotted versus time by a recorder.

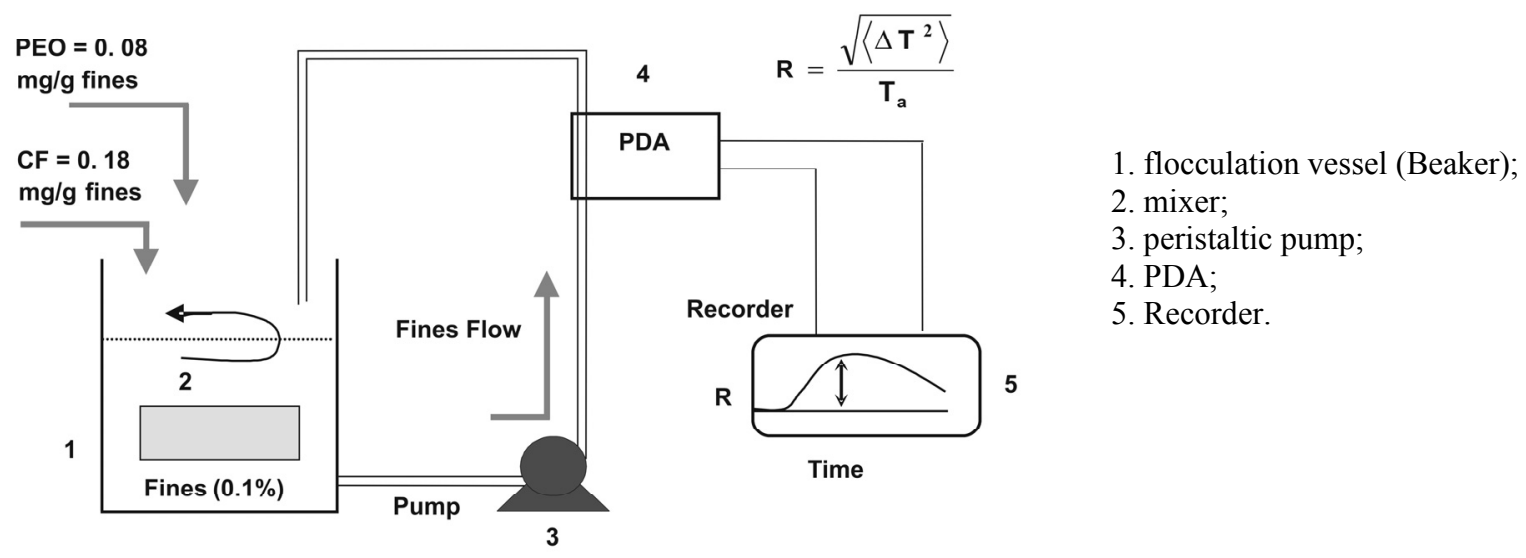

Figure 2: Experimental set up for the flocculation process

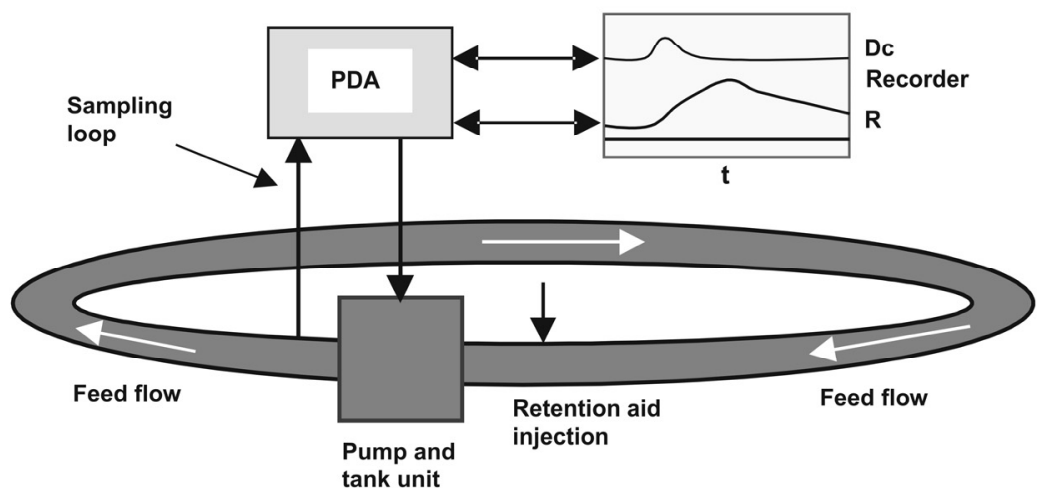

Figure 3: Flow loop as the flocculation unit for fines at high turbulent effective shear rates ( $\left.G_{\text {eff }}\right)$. 
Flocculation output was transformed into voltage signals by the PDA and recorded as Dc and $\mathrm{R}$ readings. The $\mathrm{Dc}$ from the light intensity transmitted through the suspension to the photocell indicated the particle concentration. The signal $\mathrm{R}$ indicates the root mean square (rms) of the particle number or simply the particle size (Rank Brothers Ltd, England), expressed as the rms of fluctuations in light transmittance; $R\left(=\sqrt{\left\langle\Delta \mathrm{T}^{2}\right\rangle} / \mathrm{T}_{\mathrm{a}}\right)$, where: $\Delta \mathrm{T}^{2}=\left(\mathrm{T}-\mathrm{T}_{\mathrm{a}}\right)^{2}, \mathrm{~T}$ is light transmittance and $\mathrm{T}_{\mathrm{a}}$ is the average of light transmittance (van de Ven, 1993). The $R$ reading is a measure of the flocculation intensity in arbitrary units (A.U.) of the vertical distance the pen moved. The slope value of the $R$ curve (Fig. 4) at the initial time or the initial rate of flocculation $\mathrm{r}_{\mathrm{f}}\left(=\mathrm{A}_{\mathrm{m}} / \tau\right)$ in A.U./ time also indicates the flocculation intensity. The amplitude $\left(A_{m}\right)$ is taken at equilibrium and the time required to reach equilibrium at the initial rate is the characteristic time of flocculation $(\tau)$. The actual time needed to reach equilibrium is the equilibrium time of flocculation $\left(\tau_{\mathrm{e}}\right)$.

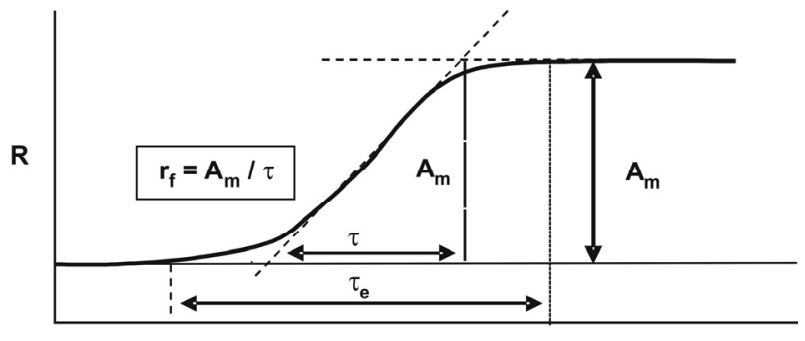

Time $\mathbf{t}$

Figure 4: The ratio reading, $\mathrm{R}$, a measure of flocculation intensity with time $t ; r_{f}=$ initial rate of flocculation; $A_{m}=$ amplitude of flocculation at equilibrium; $\tau=$ characteristic time of flocculation; $\tau_{\mathrm{e}}=$ equilibrium time of flocculation.

\section{RESULTS AND DISCUSSION}

In fines flocculation at low shear rate, two sets of flocculation experiments were performed at low magnetic stirring rate in a beaker. In the first set, PEO was used alone as a retention aid. In the second, CF was added prior to PEO. In both sets, fines flocculation at low shear rate was observed and is compared in Fig. 5. Based on the literature, the flocculation by PEO alone can be ascribed to asymmetric bridging (Carignan et al., 1998). Addition of $\mathrm{CF}$ caused a large increment in flocculation amplitude $\mathrm{A}_{\mathrm{m}}(=\mathrm{A} \times 10)$ and rate $r_{f}(=k \times 100)$. A change in the characteristic time of flocculation $\tau$ is quite necessary, since it indicates the speed of the flocculation process. Fig. 5 shows that CF caused a decrease in $\tau$ of four magnitudes. Such information for $\tau$ is important for flocculation unit design and for the selection of points of addition of retention aid on the flocculation line. Furthermore, comparison of flocculation amplitude $\mathrm{A}_{\mathrm{m}}(=\mathrm{A} \times 10)$ and rate $r_{f}(=k \times 100)$ for the two sets (Fig. 5) shows the significant increase that $\mathrm{CF}$ can cause. This result indicates that PEO alone can flocculate small fines, fillers and colloids in general, while the CF-PEO system can be used for a larger scale of particle size, colloids, fines, fibrils and fibers.

To study the flocculation process at high effective shear rate $\mathrm{G}_{\text {eff }}$ approaching that in some papermaking mills, the flocculation experiment was performed in a flow loop (Fig. 3) with the following flow properties: $v=2 \mathrm{~m} / \mathrm{s} ; \mathrm{G}=100 \mathrm{~s}^{-1} ; \operatorname{Re}=8 \times$ $10^{4} ; \mathrm{G}_{\text {eff }}=2.83 \times 10^{4} \mathrm{~s}^{-1}$. Fines flocculation was performed in two sets of experiments with the results shown in Table 1. In the first set, PEO was added alone and the results show a constant $\mathrm{R}$ reading with time: $A_{m}=r_{f}=0$. In the second set, CF was added prior to $\mathrm{PEO}$ and the results show an increase in the $R$ reading with time with significant $A_{m}$ and $r_{f}$. Given the significant $A_{m}$ and $r_{f}$ obtained with PEO alone at low shearing (Fig. 5) where PEO flocculated fines, the absence of flocculation at high $\mathrm{G}_{\text {eff }}$ can now be related to a high rate of detachment of formed flocs that are instantly dispersed by $\mathrm{G}_{\text {eff }}$. Addition of $\mathrm{CF}$ at high $\mathrm{G}_{\text {eff }}$ results in flocs that resist dispersion, indicating that $\mathrm{CF}$ strengthens the bridging bond between PEO and surfaces in a floc. This agrees with results in the literature ascribing flocculation with $\mathrm{CF}$ to induced-PEO association bridging (van de Ven et al., 1996).

Comparison of fines flocculation with the CFPEO system at high $G_{\text {eff }}$ and low shear rate is shown in Fig. 6. Small differences in the amplitude $\mathrm{A}_{\mathrm{m}}(=\mathrm{A} \times 10)$ indicate small differences in floc size. With the shear rate increase, the decrease in rate $r_{f}(=k \times 100)$ and the characteristic time $\tau$ increase show the effects of high $G_{\text {eff }}$ and turbulence in causing slower flocculation. In Flocculation Unit design, the importance of $\tau$ is clearly noticed when a Unit has processes with different $\tau$, that with lower $\tau$ being the faster. All performed experiments showed $\tau<\tau_{\mathrm{e}}$ as defined in Fig. 4. A knowledge of $A_{m}, \tau$, and $\tau_{e}$ is quite 
necessary. For a Unit of volume $\mathrm{V}$ with a Volumetric flow rate $\mathrm{Q}$, the residence time will be $\tau_{\mathrm{r}}(=\mathrm{V} / \mathrm{Q})$. In Unit design, the following order should be taken: $\tau_{\mathrm{r}}>\tau_{\mathrm{e}}>\tau$. Since PEO flocculates small particles: fines (Carignan et al., 1998) and colloids (Pelton et al., 1980), and CF-PEO flocculates fines and deposits fines on fibers (Abdallah, 2002), we can use CF-PEO to treat systems having particles of different sizes, such as waste water, followed by filtration. In such a treatment, fiber is added first followed by $\mathrm{CF}$ and PEO. The flocs along with some free particles will deposit on the fibers. In filtration, fibers with particles deposited on them form a network in which free particles are trapped.

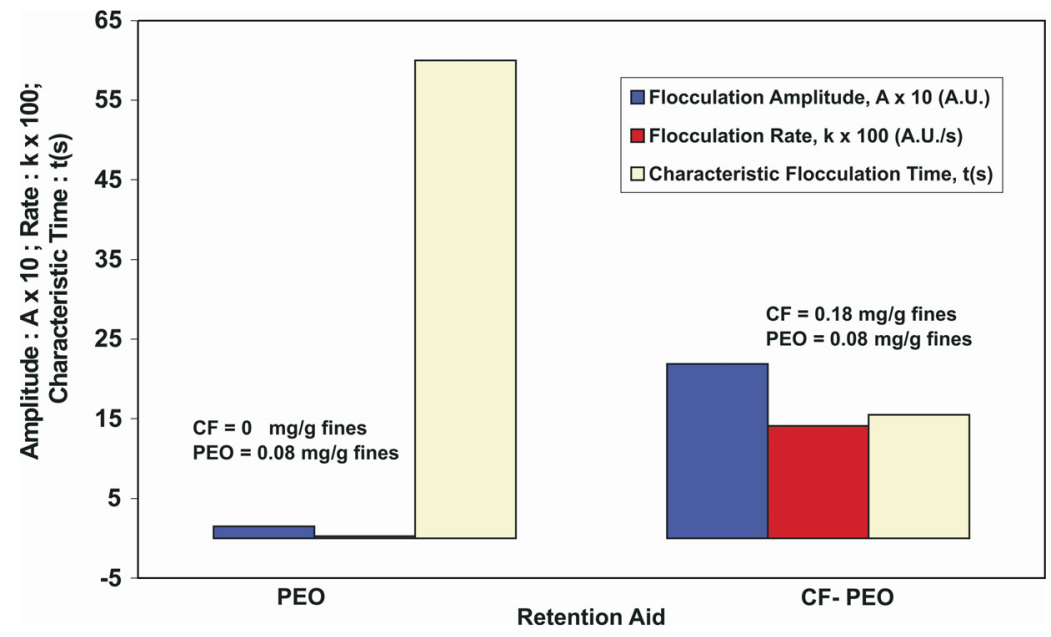

Figure 5: Fines flocculation with PEO and with CF-PEO in a beaker at low shear rate.

Table 1: Fines flocculation characteristics in a high shear and turbulent flow loop.

\begin{tabular}{|c|l|c|c|c|c|}
\hline \multicolumn{2}{|c|}{ Experiment } & $\begin{array}{c}\text { Amplitude } \times 10 \\
\text { (A.U.) }\end{array}$ & $\begin{array}{c}\text { Rate } \times 100 \\
(\text { A.U./s) }\end{array}$ & $\begin{array}{c}\text { Characteristic } \\
\text { Time (s) }\end{array}$ & Result \\
\hline 1 & CF-PEO & $\mathrm{A}_{\mathrm{m}}=24.5$ & $\mathrm{r}_{\mathrm{f}}=5.8$ & $\tau=42$ & Flocculation \\
2 & PEO only & $\mathrm{A}_{\mathrm{m}}=0$ & $\mathrm{r}_{\mathrm{f}}=0$ & - & Dispersion \\
\hline
\end{tabular}

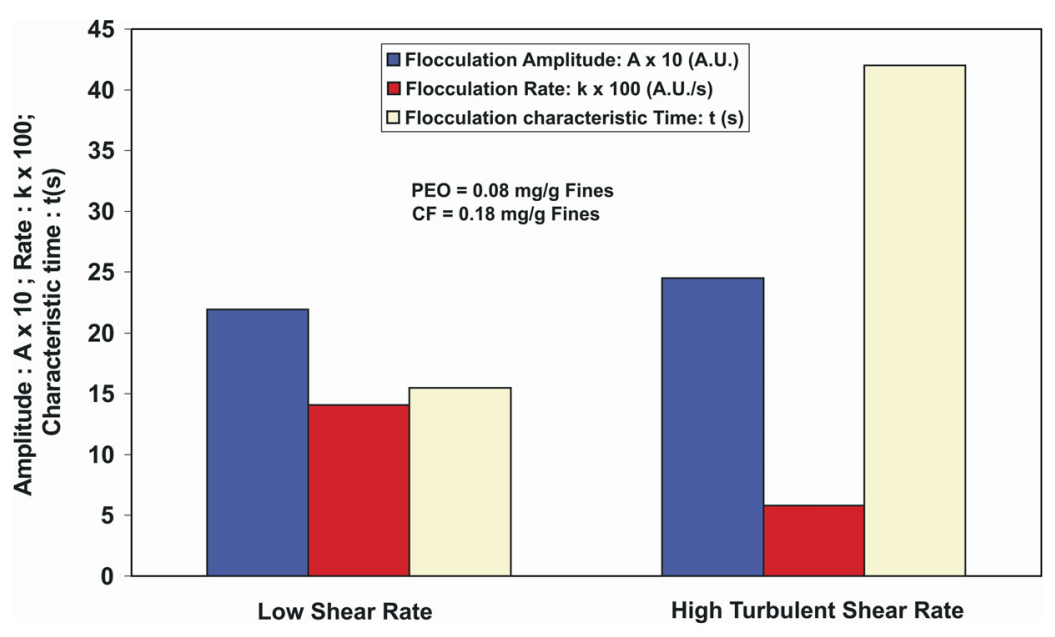

Figure 6: Comparison between fines flocculation with CF-PEO at low shear rates in a beaker and at high turbulent shear rate in flow loop. 


\section{CONCLUDING REMARKS}

We have shown that CF-PEO is an effective retention aid system. PEO alone flocculates fines by an asymmetric bridging mechanism. Addition of $\mathrm{CF}$ enhances flocculation with induced PEO association bridging, showing its important roles: stiffening PEO coils that enhances its flocculation efficiency; strengthening the bridging bond of PEO with surfaces to resist turbulence and high shears. With $\mathrm{CF}$ addition, large flocs of fines (sizes $>76 \mu \mathrm{m}$ ) exist at high effective shears and smaller flocs of colloids at lower shears on the micro scale can surely show better resistance to high turbulent shears than fines. The CF-PEO system also shows its ability to flocculate particles of various size scales and over a wide range of turbulence and shears. As a result, the CF-PEO retention aid system can be applied in wide variety of applications where particles exist, mainly in industry and in water treatment processes.

\section{NOMENCLATURE}

\section{Parameters}

$\begin{array}{ll}\mathrm{A}_{\mathrm{m}} & \begin{array}{l}\text { Amplitude of flocculation at } \\ \text { equilibrium } \\ \mathrm{T}_{\mathrm{a}}\end{array} \\ \mathrm{d} & \begin{array}{l}\text { Average light transmittance } \\ \text { Diameter of loop tube }\end{array} \\ \mathrm{k}^{-1} & \begin{array}{l}\text { Electrical double layer } \\ \text { thickness }\end{array} \\ \mathrm{G}_{\text {eff }} & \text { Effective shear rate } \\ \mathrm{r}_{\mathrm{f}} & \text { Initial rate of flocculation } \\ \mathrm{M}_{\mathrm{w}} & \text { Molecular weight } \\ \mathrm{r} & \text { Radius of loop tube } \\ \mathrm{R} & \text { Ratio reading } \\ \mathrm{Re} & \text { Reynolds number } \\ \mathrm{G} & \text { Simple shear rate } \\ \mathrm{t} & \text { time } \\ \mathrm{T} & \text { Transmittance of light } \\ \mathrm{V} & \text { Volume of a Unit } \\ \mathrm{Q} & \text { Volumetric flow rate }\end{array}$

\section{Greek Letters}

$\begin{array}{ll}\varphi & \text { CF to PEO ratio } \\ \tau & \begin{array}{l}\text { Characteristic time of } \\ \text { flocculation }\end{array} \\ \tau_{\mathrm{e}} & \text { Equilibrium time } \\ \delta & \text { Polymer layer thickness }\end{array}$

$$
\begin{array}{ll}
\tau_{\mathrm{r}} & \text { Residence time } \\
\mathrm{v} & \text { Velocity of flow }
\end{array}
$$

\section{Acronyms}

$\begin{array}{ll}\text { A.U. } & \text { Arbitrary unit } \\ \text { CF } & \text { Cofactor } \\ \text { Dc } & \text { Direct current voltage } \\ \text { PDA } & \text { Photometric Dispersion } \\ & \text { Analyzer (PDA). } \\ \text { MPR } & \text { Modified phenolic resin } \\ \text { PFR } & \text { Phenol formaldehyde resin } \\ \text { PEO } & \text { Polyethylene oxide } \\ \text { rms } & \text { root mean square } \\ \text { SNS } & \text { Sodium naphthalene } \\ & \text { sulphonate } \\ \text { SKL } & \text { Sulphonated kraft lignin } \\ \text { TA } & \text { Tannic acid }\end{array}$

\section{REFERENCES}

Abdallah, M. R., The Role of Polymer Entanglements in Polyethylene Oxide (PEO) Induced Fines Flocculation. Ph.D. Thesis, McGill University (2002).

Carignan, A., Garnier. G., van de Ven T. G. M., The Flocculation of Fines by PEO/ Cofactor Retention Aid Systems. J. Pulp. and Paper Sc., 24, No. 3, 94-99 (1998).

De Witt, J. A., van de Ven, T. G. M., The Effect of Neutral Polymer and Electrolyte on the Stability of Aqueous Polystyrene Latex. Adv. Colloid Inter. Sci., v. 42, p. 41 (1992).

Ishimaro, Y., Lindström T., Adsorption of Water Soluble, Nonionic Polymers onto Cellulosic Fibers. J. Appl. Polymer Sci., v. 29, p. 1675 (1984).

Lindström, T., Glads-Nordmark, G., Flocculation of Latex and Cellulose Dispersion by Means of Transient Polymer Networks. Colloids Surfaces, v. 8, No. 4, p. 337-351 (1984).

Meng, R. Wu., Jean, P., van de Ven, T. G. M., Flocculation of Paper making Fines by Poly(ethylene oxide) and Various Factors: Effect of PEO Entanglement, Salt and Fines. Colloids and Surfaces A: Physicochem. Eng. Aspects, v. 303, No. 3, p. 211-218 (2007).

Meng, R. Wu., van de Ven, T. G. M., Flocculation and Reflocculation: Interplay Between the Adsorption Behavior of the Components of a Dual Flocculant. Colloids and Surfaces A: Physicochem. Eng. Aspects, 341, 40-45 (2009). 
Pelton, R. H., Allen, L. H., Nugent, H. M., Factors affecting the effectiveness of some retention aids in newsprint pulp. Svensk PapperstidningNordisk Cellulosa, 83, 251-258 (1980).

Picaro, T., van de Ven, T. G. M., Dilute aqueous poly(ethylene oxide) solutions through packed beds of pulp fibers. J. Pulp. Paper Sci., v. 21, No. 1, p. 13 (1995).

Polverari, M., van de Ven, T. G. M., Dilute aqueous poly(ethylene oxide) solutions: clusters and single molecules in thermodynamic equilibrium. The Journal of Physical Chemistry, v. 100, p. 1368713695 (1996).

Rank Brothers Ltd, Photometric Dispersion Analyzer PDA 2000, Operating Manual. High street. Bottisham. Cambridge. CB5 9DA. England.

van de Ven, T. G. M., Allince, B., Associationinduced polymer bridging: new insights into the retention of fillers with PEO. J. Pulp Paper Sci., v. 22 , No. 7, p. 257-263 (1996). van de Ven, T. G. M., Abdallah Qasaimeh M., Pigeon C., Paris J., PEO-induced flocculation of fines: effect of PEO dissolution conditions and shear history. Colloids and Surfaces A: Physicochem. Eng. Aspects, 248, 151-156 (2004).

van de Ven, T. G. M., Abdallah Qasaimeh M., Pigeon C., Paris J., The Effect of Calcium Ions on the Efficiency of Polyethylene Oxide - Cofactor Retention Aid Systems, Colloids and Surfaces A: Physicochem. Eng. Aspects, 297, 79 - 83 (2007).

van de Ven, T. G. M., Kinetic Aspects of Polymer and Polyelectrolyte Adsorption on Surfaces, Adv. Colloid Inter. Sci., 48, 121-140 (1994).

van de Ven, T. G. M., Mechanism of Fines and Filler Retention with PEO/Cofactor Dual Retention Aid Systems. J. Pulp and Paper Sc., v. 23, No. 9, p. 447-451 (1997).

van de Ven, T. G. M., Particle Deposition on Pulp Fibers. Nordic Pulp and Paper Research Journal, 8, No. 1, 130-134 (1993). 